\title{
EXPERIÊNCIA DE FAMILIARES DE RECÉM-NASCIDO PREMATUROS NA UNIDADE DE TERAPIA INTENSIVA NEONATAL.
}

\author{
Gabriela Santos Silva ${ }^{1}$; Luciano Marques dos Santos ${ }^{2}$; Taynara Bispo Conceição ${ }^{3}$. \\ 1. Voluntária PEVIC, Graduanda em Enfermagem, Universidade Estadual de Feira de Santana, e-mail: \\ gabisilva93@hotmail.com \\ 2. Orientador, Departamento de Saúde, Universidade Estadual de Feira de Santana, e-mail: \\ lucmarxenfo@yahoo.com.br \\ 3. Participante do Núcleo Interdisciplinar de Estudos sobre Desigualdades em Saúde, Universidade Estadual de Feira \\ de Santana, e-mail: taynara_tatay@hotmail.com
}

PALAVRAS-CHAVE: uma; duas; três.

\section{INTRODUÇÃO}

A ocorrência de um parto prematuro e a notícia de necessidade de um tratamento especializado que implicará permanência do recém-nascido no hospital desmitifica essa idealização de perfeição do momento do parto e trás consigo sentimentos de angustia, desespero, insegurança quanto ao futuro que acaba de se tornar incerto e surpresa pela ocorrência de tal fato repentino (OLIVEIRA et al., 2013).

Dentro dessa perspectiva é notada a necessidade de um olhar diferenciado aos sentimentos e experiências desses familiares nesse contexto, em especial ao pai, avós e irmãos que são afetados de forma direta, mas que muitas vezes são esquecidos já que a maioria das ações planejadas são direcionadas a genitora (SANTOS et al., 2012).

\section{MATERIAL E MÉTODOS}

Trata-se de um estudo qualitativo, descritivo e exploratório, vinculado à pesquisa multicêntrica "Parto prematuro: estudo dos fatores associados para construção de estratégias de prevenção". Realizado nas Unidades de Terapia Intensiva Neonatal do Hospital Geral Clériston Andrade e Hospital Inácia Pinto dos Santos em Feira de Santana na Bahia.

A análise temática é uma das fases da Análise de Conteúdo preconizada por Bardin (2011), onde o tema é o conceito central. A análise temática tem o "tema" como unidade de registro e "consiste em descobrir os 'núcleos de sentido' que compõe a comunicação e cuja presença, ou frequência de aparição podem significar alguma coisa para o objetivo cuja análise se justifique (BARDIN, 2011, p. 105).

\section{RESULTADOS}


Foram obtidas quatro categorias e suas respectivas subcategorias: Sendo uma experiência inicialmente marcada pelo sofrimento (tendo medo da hospitalização na UTIN, sendo uma experiência triste devido aos aparelhos utilizados no RN e acreditando que o RN estaria mais seguro se não estivesse na UTIN); Sendo uma experiência difícil na rotina da família (sendo uma experiência que atrapalha a rotina da família e reorganizando a família para estar mais próxima da experiência); Buscando se fortalecer ao longo da experiência (pedindo forças a Deus e crendo na possibilidade de recuperação do prematuro); Sentindo-se mais tranquilos ao longo da experiência (sentindo-se aliviado ao ver a recuperação clínica do prematuro e crendo que a UTIN é necessária para recuperação do prematuro). Estas são apresentadas a seguir.

\section{SENDO UMA EXPERIENCIA MARCADA INICIALMENTE PELO SOFRIMENTO}

Tendo medo da hospitalização na UTIN

A família do recém-nascido prematuro vivencia a sua hospitalização na UTIN com intenso sofrimento, marcado pela incerteza do que virá a acontecer nos dias subsequentes e devido à crença de que a qualquer momento os trabalhadores deste setor hospitalar poderá dar-lhes notícias ruins com relação à situação clínica do mesmo.

Sendo uma experiência triste devido aos aparelhos utilizados no RN

Ver o RN com a saúde frágil, e cercado por aparelhos e dispositivos utilizados no suporte terapêutico, trouxe aos familiares o sentimento de tristeza, pois o mesmos associam tal condição com o possível sofrimento do RN.

Acreditando que o RN estaria mais seguro se não estivesse na UTIN

Além de se apresentar como um local de risco, a UTIN se demonstra como uma barreira de contato entre o familiar e o recém nascido, e, apesar de toda equipe e aparato oferecidos, o recém nascido só estaria em segurança se estivesse em seu ceio familiar, como é demonstrado na fala a seguir:

\section{SENDO UMA EXPERIÊNCIA DIFÍCIL NA ROTINA DA FAMÍLIA}


Sendo uma experiência que atrapalha a rotina da família

A hospitalização e o nascimento levaram a uma alteração de forma significativa e repentina na rotina familiar, pois os mesmos colocam o recém-nascido como prioridade, por considerar-se responsáveis pelo cuidado. Assim, os familiares abstiveram-se de suas necessidades pessoais e profissionais para estarem mais próximos da situação.

Reorganizando a família para estar mais próxima da experiência

O processo de hospitalização leva o familiar a vivenciar preocupações diárias, tendo em vista a ausência de informações sobre o que está acontecendo com a puérpera e o recém-nascido prematuro. Isso os mobiliza a buscar alguma alternativa viável para acompanhar mais de perto a hospitalização, levando-o a decidir por ficar no hospital, por entender que são importante rede de apoio efetiva tanto para a puérpera como para o $\mathrm{RN}$.

\section{BUSCANDO SE FORTALECER AO LONGO DA EXPERIÊNCIA}

Pedindo forças a Deus

Ter um filho prematuro hospitalizado na UTIN faz a família sentir-se sem forças para enfrentar e superar a experiência, por isso, durante a experiência os mesmos recorrem à figura divina como recurso para enfrentar a situação inicialmente difícil e assim acreditar que tudo será bem resolvido.

Crendo na possibilidade de recuperação do prematuro

Apesar de entender que a imaturidade orgânica pode levar a riscos durante a estadia na UTIN, os entrevistados, ao verem o prematuro lutando pela vida, se mobilizam e demonstram esperança na sua recuperação clínica e consequente alta. 


\section{SENTINDO-SE MAIS TRANQUILOS AO LONGO DA EXPERIÊNCIA}

Sentindo-se aliviado ao ver a recuperação clínica do prematuro

Os entrevistados demonstram alivio depois de contato e ao receber noticias a cerca do estado do recém-nascido, pois acompanham a boa evolução clínica do mesmo. Vivenciar a estabilidade clinica do prematuro tornou-se uma experiência mais agradável para o entrevistado.

Crendo que a UTIN é necessária para recuperação do prematuro

Ao longo da hospitalização na UTIN, presenciar a recuperação clinica do prematuro e entender que a UTI não é um local de morte, mas sim que potencializa a vida e que é importante para a recuperação do prematuro, fez o familiar sentir-se mais tranquilo diante a experiência.

\section{DISCUSSÃO}

O processo gestacional gera nos familiares expectativas enormes, dentre elas um nascimento termo e saudável, onde o recém-nascido possa ir para casa após o parto. $\mathrm{O}$ nascimento prematuro vem de forma a romper essas expectativas, sendo considerado um fenômeno inesperado no contexto familiar, pois além da ocorrência súbita, a imaturidade orgânica e situação de vulnerabilidade de saúde do recém nascido (RN) trás consigo a possibilidade de internamento em uma unidade de terapia intensiva neonatal (UTIN) (SANTOS et al 2012; OLIVEIRA, 2013).

Este internamento na UTIN é cercado de inseguranças e medo do desconhecido, pois há uma crença popular de que este é um espaço hospitalar perigoso, associando internamento em unidade intensiva com morte, além de transformações no contexto familiar, alterando dinâmicas e rotinas preestabelecidas por gerar demandas e responsabilidades novas e inesperadas, ademais ocasionando um distanciamento do recém-nascido(SANTOS et al 2012; OLIVEIRA, 2013; SOARES et al 2015; BALDISSERELA; DELL'AGLIO 2009).

Além disso, a associação da UTI a um local sem esperança de vida e que interfere na interação e cuidado do recém-nascido, leva aos familiares a acharem que o ceio familiar é o local de maior controle e proteção, e que por isso o recém-nascido só estaria seguro se lá estivesse. Como o lar é um território conhecido, onde a família tem 
maior liberdade de atuação, se demonstra como um local aposto a UTI, onde, por questões de espaço e organização, limita a atuação familiar (SANTOS et al 2012).

Foi evidenciado também, que todos estes sentimentos são refletidos numa vontade aparente de acompanhamento e participação efetiva nessa experiência, por isso se nota nos depoimentos uma mobilização familiar para que todos se envolvam de maneira positiva (CENTA; MOREIRA; PINTO, 2004). Porém, alheio a essa vontade, existem alguns fatores dificultadores que acabam por interferir nesse processo.

O dilema vivenciado pelos pais e familiares de conciliarem suas rotinas profissionais e passar mais tempo com o $\mathrm{RN}$ geralmente não é resolvido, onde os mesmo só conseguem participar da experiência nos momentos em que estão disponíveis, e não de forma integral (SANTOS et al 2012).

Em meio a um processo tão estressante e de grande carga emocional, os envolvidos procuram redes de apoio, estas que vão servir como forma de força e enfrentamento da experiência. Nesta pesquisa foi observado o uso da fé e da religiosidade como rede e apoio. Assim sendo, os familiares expressaram utilizar da crença e espiritualidade como motivação e esperança de um desfecho positivo, além de trazer sensações de conforto e alivio em face da angustia consequente do internamento do RN(OLIVEIRA, 2013; ROCHA et al 2012).

Ademais, a pesar de inicialmente a situação se mostrar difícil, pois os sentimentos negativos se demonstram sobressalentes, nota-se que, com o passar do tempo a percepção de recuperação clinica do prematuro e o recebimento de informações positivas a cerca do estado do RN transformam em menos sofrida a experiência (LIMA et al 2017).

\section{CONCLUSÕES}

A realização deste estudo possibilitou compreender a experiência da família diante da hospitalização do recém-nascido prematuro em uma Unidade de Terapia Intensiva Neonatal, sendo esta se mostrado em sua maioria atrelada a sentimentos negativos como medo, insegurança e tristeza.

Tais sentimentos são relacionados ao parto prematuro, evento inesperado e de grande risco que afeta os envolvidos em inúmeras instancias. A internação na unidade de terapia intensiva intensifica ainda mais esses sentimentos, pois a UTI se demonstra incialmente como um ambiente de risco e iminência de morte. 
Os familiares buscam em sua maioria a fé e a crença em um ser superior como suporte de apoio para enfrentamento, o que lhes cerca de mais esperança e os tranquiliza.

Foi observado em grande parte dos entrevistados que o dialogo com os profissionais e o recebimento de informações reais sobre o estado do $\mathrm{RN}$ os tranquiliza e ajuda a lidar e encarar melhor a experiência, porém, apesar disso, ainda se nota um defict significativo neste dialogo. Propõe-se aos profissionais incluam a família em seu plano assistencial e os envolva no processos de cuidado, além de procurar fortalecer o relacionamento e dialogo, sendo assim prestado um cuidado holístico e mais abrangente.

\section{REFERÊNCIAS}

BALDISSARELLA, L.; DELL'AGLIO, D. D. No limite entre a vida e a morte: um estudo de caso sobre a relação pais/bebê em uma uti neonatal, Estilos da Clínica, v. 14, n. 26, p. 68-89, 2009.

BOUSSO, R. S.; SERAFIM, T. S.; MISKO, M. D. Histórias de vida de familiares de crianças com doenças graves: relação entre religião, doença e morte, Revista LatinoAmericana de Enfermagem, v.18, n. 2, t. 11-17, Mar- Abr, 2010.

CENTA M.L.; MOREIRA E.C.; PINTO M. N. G. H. R. A experiência vivida pelas famílias de crianças hospitalizadas em uma unidade de terapia intensiva neonatal, Texto \& Contexto Enfermagem, Florianópolis SC, v. 13, n. 3, p. 444-451, Jul-Set 2004.

DIAZ, Z. M.; FERNANDES, S. M. G. C.; CORREIA, S. Dificuldades dos pais com bebés internados numa Unidade de Neonatologia, Revista de enfermagem Referência. Série 4, n. 3, p. 85-93, Nov-Dez, 2014.

DUARTE, E. D.; SENA, R. R.; XAVIER, C. C. As vivências de pais e profissionais na unidade de terapia intensiva neonatal, Ciência y Enfermaría, n. 15, v. 2, p. 77-86, 2011.

FRIGO, J.; ZOCCHE, D. A. A.; PALAVRO, G. L.; TURATTI, L. A.; NEVES, E. T.; SCHAEFER, T. M. Percepções de pais de recém-nascidos prematuros em unidade de terapia intensiva neonatal, Revista de Enfermagem da UFSM, v. 5, n. 1, p. 58-68, JunMar, 2015.

LIMA, V. F.; MAZZA, V. A.; MOR, L. M.; PINTO, M. N. G. R. Vivência dos familiares de prematuros internados em unidade de terapia intensiva neonatal, Revista Mineira de Enfermagem, Out 2017.

ROCHA, L.; MONTICELLI, M.; MARTINS, A.; SCHEIDT, D.; COSTA, R.; BORCK, M.; BURIGO, R. A. Sentimentos paternos relacionados à hospitalização do filho em unidade intensiva neonatal, Revista de Enfermagem da UFSM, Santa Maria RS, v. 2, n. 2, p. 264-274, Mai-Ago 2012. 
SANTOS, L. M.; SILVA, C. L. S.; SANTANA, R. C. B.; SANTOS V. E. P. Vivências paternas durante a hospitalização do recém-nascido prematuro na Unidade de Terapia Intensiva Neonatal, Revista Brasileira de Enfermagem, Brasília DF, v. 65, n. 5, p. 788-794, Set-Out 2012.

SOARES, R. L. S. F.; CHRISTOFFEL, M. M.; RODRIGUES, E. C.; MACHADO, M. E. D.; CUNHA, A. L. Ser pai de recém-nascido prematuro na unidade de terapia intensiva neonatal: da parentalidade a paternidade, Escola Anna Nery, v. 19, n. 3, p. 409-416, 2015.

OLIVEIRA, K.; VERONEZ, M.; HIGARASHI, I. H.; CORREAA, D. A. M. Vivências de familiares no processo de nascimento e internação de seus filhos em uti neonatal. Esc Anna Nery, 17 (1):46-53, Jan -Mar 2013. 